\title{
Hierarchical Silver Indium Tungsten Oxide Mesocrystals with Morphology-, Pressure-, and Temperature-Dependent Luminescence Properties
}

\author{
Bo Hu${ }^{1}$, Li-Heng Wu${ }^{1}$, Zhi Zhao ${ }^{2}$, Meng Zhang ${ }^{1}$, Shao-Feng Chen ${ }^{1}$, Shu-Juan Liu ${ }^{1}$, Hong-Yan Shi ${ }^{1}$ Ze-Jun Ding ${ }^{3}$, \\ and Shu-Hong $\mathrm{Yu}^{1}(\bowtie)$ \\ ${ }^{1}$ Division of Nanomaterials and Chemistry, Hefei National Laboratory for Physical Sciences at the Microscale, Department of Chemistry, \\ Department of Materials Science and Engineering, the National Synchrotron Radiation Laboratory, University of Science and Technology \\ of China, Hefei 230026, China \\ ${ }^{2}$ Division of Instruments Center for Physical Science, Hefei National Laboratory for Physical Sciences at the Microscale, University of \\ Science and Technology of China, Hefei 230026, China \\ ${ }^{3}$ Department of Physics, Hefei National Laboratory for Physical Sciences at the Microscale, University of Science and Technology of \\ China, Hefei 230026, China
}

Received: 1 November 2009 / Revised: 26 February 2010 / Accepted: 1 April 2010

C The Author(s) 2010. This article is published with open access at Springerlink.com

\begin{abstract}
Highly hierarchical structures of silver indium tungsten oxide $\left(\operatorname{Ag} \operatorname{In}\left(\mathrm{WO}_{4}\right)_{2}\right)$ mesocrystals can be rationally fabricated via the microwave-assisted synthesis method by tuning the initial concentrations of the precursors. Photoluminescence spectra of hierarchical $\operatorname{AgIn}\left(\mathrm{WO}_{4}\right)_{2}$ mesocrystals were measured to investigate the correlation between the morphology, pressure, and temperature and their luminescence properties. The materials showed interesting white emission when excited by visible light of wavelength $460 \mathrm{~nm}$. $\mathrm{AgIn}\left(\mathrm{WO}_{4}\right)_{2}$ materials having different morphologies displayed notable differences in photogenerated emission performance. The emission was strongly correlated with the surface nanostructures of outgrowths, with larger amounts of outgrowths leading to stronger emission intensities. The pressure- and temperature-dependent photoluminescence properties of these materials have also been investigated under hydrostatic pressures up to $16 \mathrm{GPa}$ at room temperature and in the temperature range from 10 to $300 \mathrm{~K}$.
\end{abstract}

\section{KEYWORDS}

Photoluminescence, AgIn $\left(\mathrm{WO}_{4}\right)_{2}$, mesocrystal, morphology, high-pressure, temperature

\section{Introduction}

The special properties of nanomaterials have attracted increasing attention over the last decades. It has been shown that the properties of nanomaterials can be controlled by tailoring their size, shape, chemical composition, and surface functional groups [1]. The superior photoluminescence (PL) properties of semiconductor materials give rise to promising applications in solar cells, light-emitting diodes, biological labeling, and optical sensing $[2,3]$. Metal tungstates are important semiconductors because of their potential applications in photoluminescence [4], catalysis [5], optics [6], humidity sensors [7], and magnetics [8].

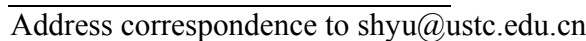


Achieving precise control over the synthesis and properties of metal tungstates has been a hot research subject. The optical properties of metal tungstates with different morphologies have been studied [9-11] Su et al. [12] have reported that the physical properties of $\mathrm{CaWO}_{4}$ nanocrystals are size-dependent. Rare earthdoped $\mathrm{CaWO}_{4}$-based phosphors have displayed excellent luminescence properties with luminescence lifetimes of milliseconds, abnormally narrow emissions, and maximum quantum efficiencies of $92 \%$ [13, 14].

Branched nanostructures, a unique class of materials, have sharp tips attached on a long backbone $[15,16]$. These nanostructured tips are stabilized on larger structures and have possible applications in multifunctional single-component nanodevices [17-19]. The hierarchical structure results in a remarkable enhancement in their properties due to their large surface area and branch contributions [20-22]. For example, Wang et al. [23] have reported the excellent field-emission properties of aluminum nitride nanorods with multi-tipped surfaces, and single-crystalline branched zinc phosphide nanostructures have displayed highly efficient spatially resolved photodetector characteristics [24].

The properties of semiconductors are highly dependent on their structural form. Morphologydependent luminescence properties of semiconductors have been widely studied [25-29]. For example, Kan et al. have convincingly established that the electronic structure and optical properties of InAs quantum rods are highly shape-dependent [30]. Moreover, Zhai et al. have reported morphology-dependent stimulated emission and field emission of ordered CdS nanostructure arrays by rationally tuning the structure alignment of the arrays, demonstrating that the better the structure alignment, the lower the threshold for a stimulated emission [31]. Recently, we have synthesized a new kind of silver indium tungsten oxide $\left(\mathrm{AgIn}\left(\mathrm{WO}_{4}\right)_{2}\right)$ mesocrystals with highly hierarchic structures using a microwave-assisted approach. The materials show high and selective photocatalytic activity for the degradation of different organic dyes under UV and visible light irradiation [32].

Herein, we report a systematic study of the morphology-, pressure-, and temperature-dependent photoluminescence properties of such hierarchical silver indium tungsten oxide $\left(\mathrm{AgIn}\left(\mathrm{WO}_{4}\right)_{2}\right)$ mesocrystals with branched nanostructures. A variety of different structures were prepared by carefully tuning the initial concentrations of the precursors.

\section{Experimental}

The hierarchical AgIn $\left(\mathrm{WO}_{4}\right)_{2}$ mesocrystals were prepared by a microwave-assisted synthesis method described previously [32]. In short, an aqueous solution containing both $\mathrm{AgNO}_{3}(0.1 \mathrm{mmol} / \mathrm{L})$ and $\mathrm{In}\left(\mathrm{NO}_{3}\right)_{3} \cdot 4.5 \mathrm{H}_{2} \mathrm{O}(0.1 \mathrm{mmol} / \mathrm{L})$ was mixed with an equal volume of an aqueous solution of $\mathrm{Na}_{2} \mathrm{WO}_{4} \cdot 2 \mathrm{H}_{2} \mathrm{O}$ $(0.2 \mathrm{mmol} / \mathrm{L})$. The resulting white suspension was stirred for $40 \mathrm{~min} .6 \mathrm{~mL}$ of the suspension was transferred into a microwave glass vessel and heated to $180{ }^{\circ} \mathrm{C}$ by microwave irradiation under magnetic stirring for $20 \mathrm{~min}$. The precipitate was filtered off and washed with deionized water and finally air-dried at room temperature.

X-ray power diffraction (XRD) was carried out on a Philips X'Pert PRO Super X-ray diffractometer equipped with graphite monochromatized $\mathrm{Cu} \mathrm{Ka}$ radiation $(\lambda=1.54056 \AA)$ with the operating voltage and current maintained at $40 \mathrm{kV}$ and $40 \mathrm{~mA}$, respectively. Transmission electron microscope (TEM) imaging was performed on a Hitachi (Tokyo, Japan) $\mathrm{H}-800 \mathrm{TEM}$ at an accelerating voltage of $200 \mathrm{kV}$. Field emission scanning electron microscopy (FESEM) was carried out with a field emission scanning electron microanalyzer (JEOL-6700F). PL spectra were recorded on a Fluorolog-3 spectrophotometer with an Xe lamp as the excitation source at different temperatures. The microwave system was a CEM Discover Microwave Synthesizer (CEM Corporation, USA).

For the high-pressure measurements, samples were loaded into a diamond anvil cell (DAC) without using a pressure transmission medium. Pressure was measured by the ruby fluorescence method [33]. Raman and PL spectra were recorded by an integrated laser Raman system (LabRAM HR, Jobin Yvon) with a confocal microscope, stigmatic spectrometer, and a multichannel air-cooled charge-coupled device (CCD) detector with a typical resolution of $1 \mathrm{~cm}^{-1}$ in the measured frequency region. An argon ion laser operating 
at $514.5 \mathrm{~nm}$ and a power of up to $15.2 \mathrm{~mW}$ was used as the excitation source. All spectra were measured at room temperature in the backscattering geometry.

\section{Results and discussion}

The morphology, structure, and chemical composition of $\mathrm{AgIn}\left(\mathrm{WO}_{4}\right)_{2}$ mesocrystals have been reported previously [32]. The morphology of the $\operatorname{AgIn}\left(\mathrm{WO}_{4}\right)_{2}$ materials can be effectively regulated by adjusting the initial concentrations of the precursors (Fig. 1). We define $\mathrm{C}$ as a mixture of precursors with the concentrations of $\mathrm{AgNO}_{3}(0.01 \mathrm{mmol} / \mathrm{mL}), \operatorname{In}\left(\mathrm{NO}_{3}\right)_{3} \cdot 4.5 \mathrm{H}_{2} \mathrm{O}$ $(0.01 \mathrm{mmol} / \mathrm{mL})$, and $\mathrm{Na}_{2} \mathrm{WO}_{4} \cdot 2 \mathrm{H}_{2} \mathrm{O}(0.02 \mathrm{mmol} / \mathrm{mL})$. This mixture gives a material (sample 3 in Table 1) that has a hierarchical caterpillar-like architecture, including the initially formed olive-like core and striated outgrowths that are oriented vertically to the core (Figs. 1(g)-1(i)). When the concentrations in the precursor mixture were decreased from $1 \mathrm{C}$ to $0.33 \mathrm{C}$
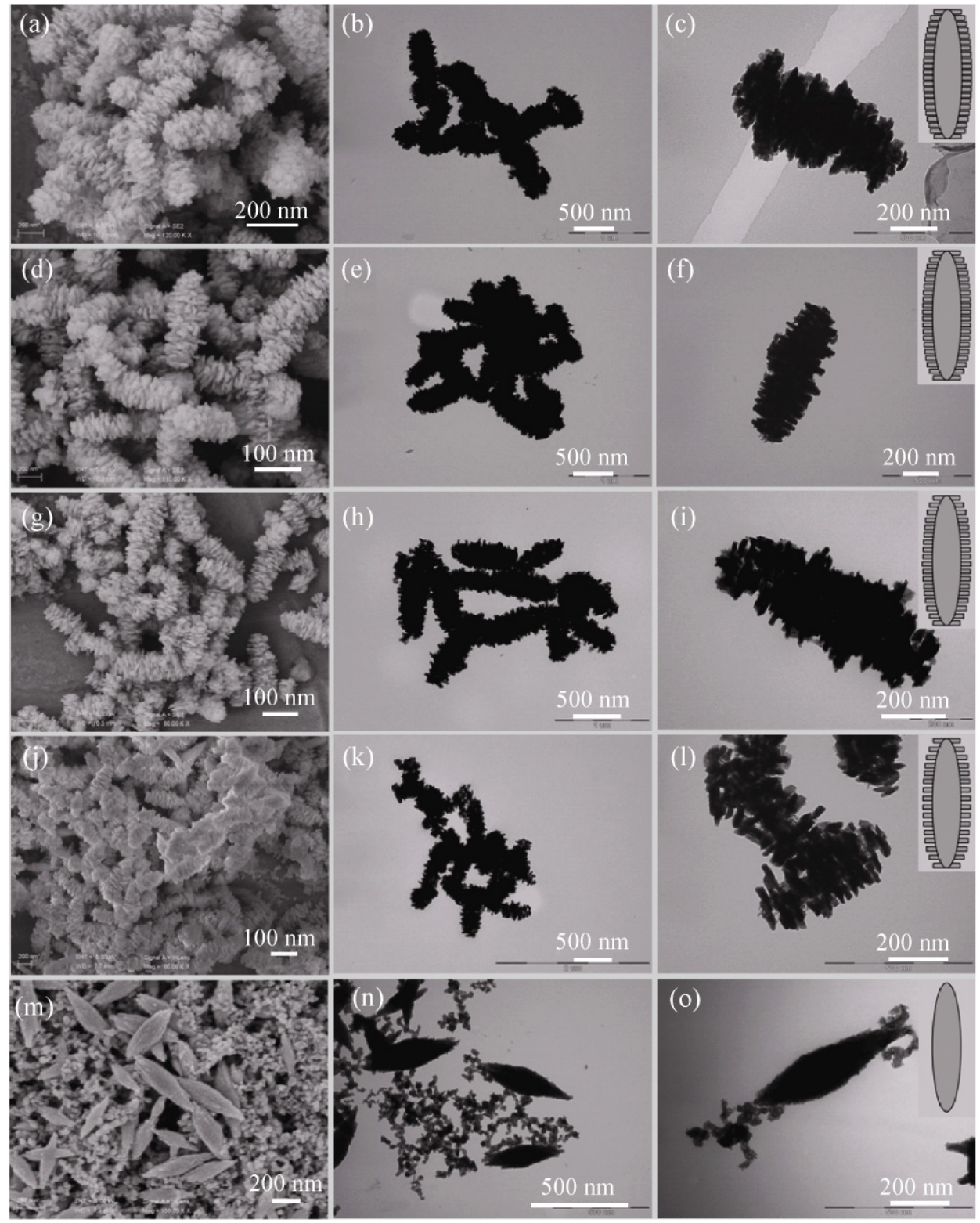

Figure 1 Typical SEM and TEM images and the corresponding geometric sketches of five $\operatorname{AgIn}\left(\mathrm{WO}_{4}\right)_{2}$ materials: (a)-(c) caterpillar-like structure (sample 1 in Table 1); (d)-(f) caterpillar-like structure (sample 2 in Table 1); (g)-(i) caterpillar-like structure (sample 3 in Table 1); (j)-(l) caterpillar-like structure (sample 4 in Table 1); (m)-(o) olive-like structure and nanoparticles (sample 5 in Table 1) 
Table 1 Morphology and calculated band gap of the as-synthesized $\operatorname{Ag} \operatorname{In}\left(\mathrm{WO}_{4}\right)_{2}$ materials (samples 1-5) prepared by adjustment of the initial concentrations of the precursors from $3 \mathrm{C}$ to $0.33 \mathrm{C}$, where $\mathrm{C}$ represents a precursor mixture in which the concentrations are $\mathrm{AgNO}_{3}(0.1 \mathrm{mmol} / \mathrm{mL}), \mathrm{In}\left(\mathrm{NO}_{3}\right)_{3} \cdot 4.5 \mathrm{H}_{2} \mathrm{O}(0.1 \mathrm{mmol} / \mathrm{mL})$, and $\mathrm{Na}_{2} \mathrm{WO}_{4} \cdot 2 \mathrm{H}_{2} \mathrm{O}(0.2 \mathrm{mmol} / \mathrm{mL})$

\begin{tabular}{cclccc}
\hline Sample & $\begin{array}{l}\text { Initial concentrations } \\
\text { of the precursor }\end{array}$ & \multicolumn{1}{c}{ Morphology } & $\begin{array}{l}\text { Diameter of central } \\
\text { part (nm) }\end{array}$ & Length (nm) & Band gap (eV) \\
\hline 1 & $3 \mathrm{C}$ & Caterpillar-like structure & $300-500$ & $700-900$ & 3.01 \\
2 & $2 \mathrm{C}$ & Caterpillar-like structure & $300-500$ & $700-900$ & 3.02 \\
3 & $1 \mathrm{C}$ & Caterpillar-like structure & $300-500$ & $700-900$ & 3.31 \\
4 & $0.5 \mathrm{C}$ & Caterpillar-like structure & $200-300$ & $400-600$ & 3.46 \\
5 & $0.33 \mathrm{C}$ & Olive-like structure and nanoparticles & $100-150$ & $400-500$ & 3.52 \\
\hline
\end{tabular}

(sample 5 in Table 1), the amount of outgrowths decreased, and the morphology changed from caterpillar-like structures to a mixture of olive-like structures and nanoparticles (Figs. $1(\mathrm{~m})-1(\mathrm{o})$ ). On further decreasing the concentrations to $0.083 \mathrm{C}$, the morphology changed to a pure olive-like structure without any outgrowths (see Fig. S-1 in the Electronic Supplementary Material (ESM)). In contrast, when the concentration was increased from $1 \mathrm{C}$ to $3 \mathrm{C}$ (sample 1 in Table 1), the amount of outgrowths increased and the caterpillar-like structures become much thicker and more massive ((Figs. 1(a)-1(c)). The UV-visible absorption spectra of the samples confirm the intrinsic semiconductor nature of these materials (see Fig. S-2 in the ESM).

Based on the above results, the morphology and calculated band gap of the products have been summarized in Table 1. Although the morphologies of these materials show dramatic changes on adjustment of the initial concentrations of the precursors, the products were well-crystalline and their XRD patterns are all in agreement with the pure monoclinic structure of $\operatorname{AgIn}\left(\mathrm{WO}_{4}\right)_{2}$ (Fig. 2).

The luminescence spectrum of the $\operatorname{AgIn}\left(\mathrm{WO}_{4}\right)_{2}$ mesocrystals prepared with the precursor concentrations of 1 C (sample 3 in Table 1) is shown in Fig. 3(a). It can be seen that the mesocrystals exhibited interesting white emission, with a broad emission band from 500 to $800 \mathrm{~nm}$ with a maximum at $560 \mathrm{~nm}$ upon excitation at $460 \mathrm{~nm}$ (Fig. 3(a)). The strong luminescence intensity indicates the good crystallinity of the mesocrystals [34]. The broad PL bands for the mesocrystals can be deconvoluted into four Gaussian curves with their maxima centered at $516 \mathrm{~nm}(2.40 \mathrm{eV}), 556 \mathrm{~nm}(2.23 \mathrm{eV})$, $600 \mathrm{~nm}(2.07 \mathrm{eV})$, and $660 \mathrm{~nm}(1.88 \mathrm{eV})$. The emission

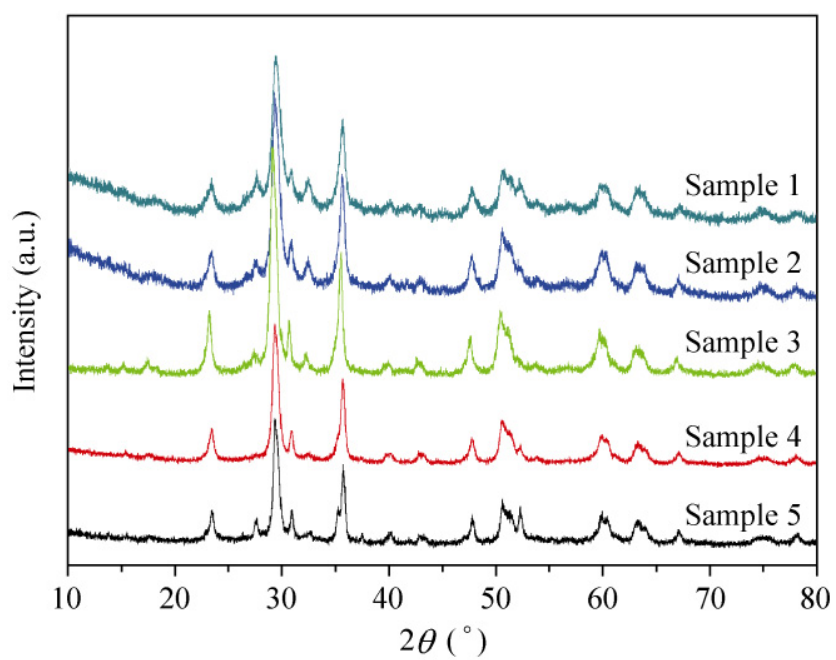

Figure 2 XRD patterns of five $\operatorname{AgIn}\left(\mathrm{WO}_{4}\right)_{2}$ materials (samples $1-5$ in Table 1)

centers of the green, orange, and red components are consistent with previous reports [35-39]. The excitation spectrum for emission at $560 \mathrm{~nm}$ showed a strong broad band from 350 to $540 \mathrm{~nm}$ (Fig. 3(b)).

The PL spectrum of this material can effectively reveal the migration, transfer, and recombination processes of photogenerated electron-hole pairs [40]. The emission maximum at $560 \mathrm{~nm}$ corresponds to an excitation process and the actual band gap in the material. The band structure of $\operatorname{AgIn}\left(\mathrm{WO}_{4}\right)_{2}$ is complex, because of the presence of three different cations and the similar geometric positions of the isoelectronic $\mathrm{Ag}^{+}$and $\mathrm{In}^{3+}$ ions. Tang et al. [40] have reported the band structure of $\operatorname{AgIn}\left(\mathrm{WO}_{4}\right)_{2}$, in which the valence band is the hybridized band of $\mathrm{Ag} 4 \mathrm{~d}$ and $\mathrm{O} 2 \mathrm{p}$, and the conduction bands are the empty $W 5 \mathrm{~d}$ and the hybridized band of $\mathrm{Ag} 5 \mathrm{~s}$ and In 5s. The emission maximum at $560 \mathrm{~nm}$ corresponds to electron excitation 


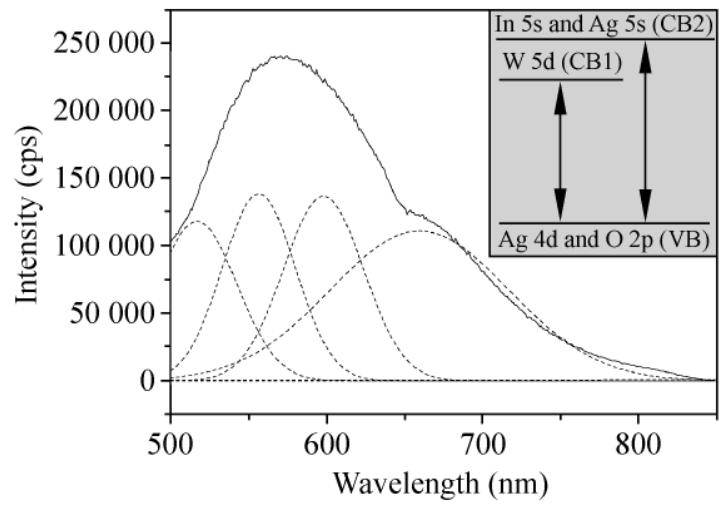

(a)

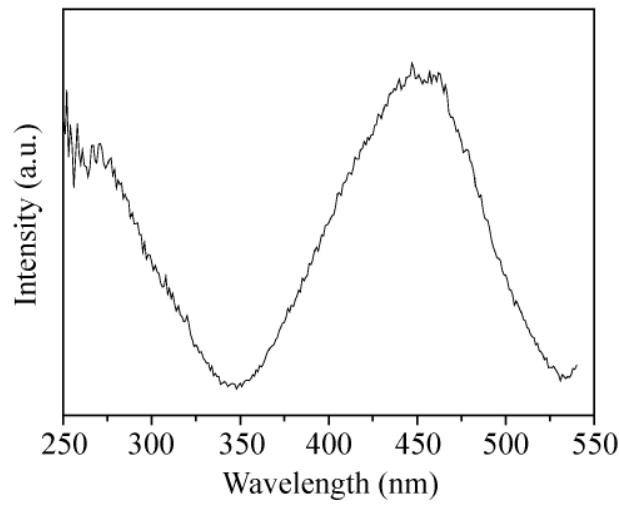

(b)

Figure 3 (a) The emission and deconvoluted PL spectrum of the $\operatorname{AgIn}\left(\mathrm{WO}_{4}\right)_{2}$ mesocrystals (sample 3 in Table 1). The excitation wavelength was $460 \mathrm{~nm}$ and the spectrum was recorded at room temperature. The insert image is a schematic illustration of the band structure of $\operatorname{AgIn}\left(\mathrm{WO}_{4}\right)_{2}$, in which VB is the valence band and $\mathrm{CB}$ is the conduction band [35, 40]. (b) The excitation spectrum of the $\mathrm{AgIn}\left(\mathrm{WO}_{4}\right)_{2}$ mesocrystals (sample 3 ) using $560 \mathrm{~nm}$ as the emission wavelength

from the hybridized band of $\mathrm{Ag} 4 \mathrm{~d}$ and $\mathrm{O} 2 \mathrm{p}$ to the $\mathrm{W}$ $5 \mathrm{~d}$ level, and is consistent with the previous report [40].

The luminescence properties of five samples of $\operatorname{AgIn}\left(\mathrm{WO}_{4}\right)_{2}$ prepared with different initial concentrations of the precursors have been studied, in order to investigate the relationship between the morphology and the luminescence of these materials. Figure 4 shows the luminescence spectra of the samples. All of the spectra consist of a broad band in the visible region. Interestingly, the luminescence intensity had a close relationship with the morphology of the sample, namely the greater the amount of outgrowths on the core, the stronger the luminescence intensity. For example, the luminescence intensity of sample 1 (Table 1) was 30 times greater than sample 5 . As shown in the insert to Fig. 4(a), there is an interesting linear relationship between the initial concentrations of the precursors (as expressed by $\mathrm{C}$ ) and the luminescence intensity of the samples.

The morphology dependence of the luminescence properties of the samples can be mainly ascribed to presence of different amounts of surface defects. For the as-synthesized $\mathrm{AgIn}\left(\mathrm{WO}_{4}\right)_{2}$ materials, the presence of crystalline outgrowths on the core results in an

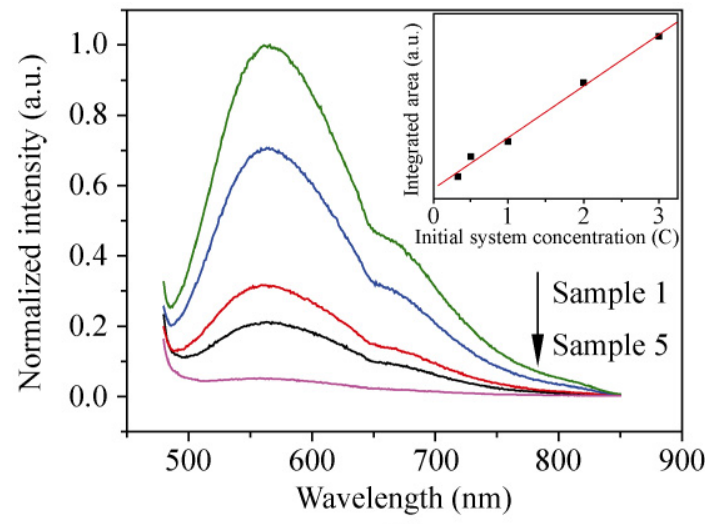

(a)

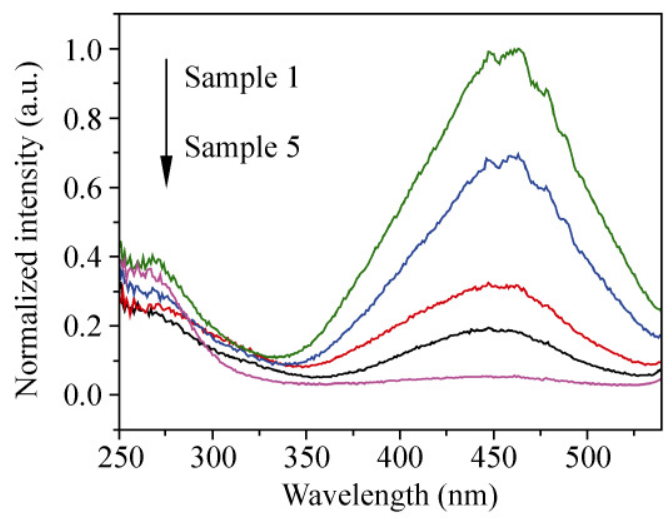

(b)

Figure 4 (a) Morphology-dependent PL spectra of $\operatorname{AgIn}\left(\mathrm{WO}_{4}\right)_{2}$ materials (samples 1-5 in Table 1). The excitation wavelength was $460 \mathrm{~nm}$ and the spectra were recorded at room temperature. The insert image shows the relationship between the initial concentrations of the precursors (as expressed by $\mathrm{C}$ ) and the luminescence intensity of the samples. The black spots represent the experimental data and the red line represents the best fit to a linear function with a linear regression equation of $y=1.52 x-2.33$ and a correlation coefficient of 0.9965. (b) The excitation spectra of the $\operatorname{AgIn}\left(\mathrm{WO}_{4}\right)_{2}$ materials (samples 1-5) using $560 \mathrm{~nm}$ as the emission wavelength 
increase in the number of surface defects. The nanostructures of crystalline outgrowths have more surface defects due to their high surface-to-volume ratios. Previous reports have demonstrated that the surface of a semiconductor plays an important role in its visible emission [41,42]. Usually, surface states are involved in nonradiative relaxation processes. The surface can strongly disturb the lattice where the high concentration of both shallow and deep levels provides a pathway for nonradiative recombination of charge carriers [42]. Electron-hole recombination at a defect site can result in a large reorganization in the local charge distribution, leading to strong vibronic transitions and broad emission bands [42]. Furthermore, a large surface-to-volume ratio of outgrowths can lead to the efficient and fast trapping of photogenerated holes at surface sites for radiative recombination of charge carriers [43, 44]. From this point of view, it can be argued that samples with more surface defects and surface nanostructures give rise to stronger emission in the visible region.

Temperature- and pressure-dependent luminescence measurements have previously been used to investigate the stability and properties of the luminescent centers in a semiconductor [45]. An externally applied hydrostatic pressure can shorten the interatomic distance and change the overlap between adjacent electronic orbitals $[46,47]$. The temperature can influence both the crystal fields surrounding luminescent centers and electron- phonon coupling [48]. To the best of our knowledge, the temperature- and pressure-dependent luminescence of $\mathrm{AgIn}\left(\mathrm{WO}_{4}\right)_{2}$ materials has not been reported until now.

Pressure-dependent changes in the luminescence spectra of $\mathrm{AgIn}\left(\mathrm{WO}_{4}\right)_{2}$ mesocrystals (sample 3) were investigated up to $16.239 \mathrm{GPa}$ using a diamond anvil cell at room temperature (Fig. 5), in which the peaks at 550 and $693 \mathrm{~nm}$ correspond to the diamond and ruby R1 bands, respectively. As the pressure was increased up to $8.714 \mathrm{GPa}$, the intensity of the spectra decreased monotonically and rapidly. When the pressure exceeded $8.714 \mathrm{GPa}$, the decrease in the intensity of the spectra became less marked with further increases in pressure. Therefore, pressure clearly has a significant influence on the luminescence intensity and the structure of the mesocrystals. The structure of the mesocrystals (sample 3) at different pressures was studied by Raman spectroscopy (Fig. 5(b)). The intensity of the characteristic Raman peaks of the mesocrystals, such as those at 760,952 , and $1120 \mathrm{~cm}^{-1}$, decreased gradually with increasing pressure. When the pressure was increased above $8.714 \mathrm{GPa}$, the Raman peak at $952 \mathrm{~cm}^{-1}$ shifted to longer wavelengths, and the Raman peak at $760 \mathrm{~cm}^{-1}$ became broader. These changes indicate that a phase transition of the material occurred above $8.714 \mathrm{GPa}$. Therefore, $8.714 \mathrm{GPa}$ is the critical value of the pressure at which the crystals undergo a pressure-induced phase transition resulting in changes in the crystal field.

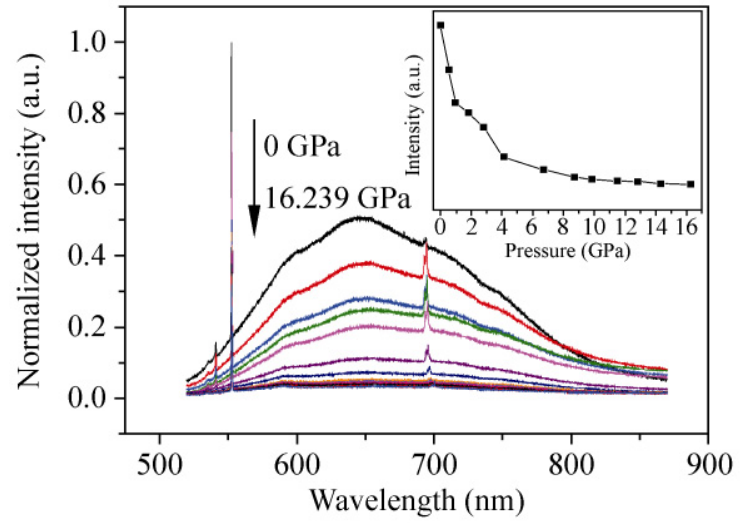

(a)

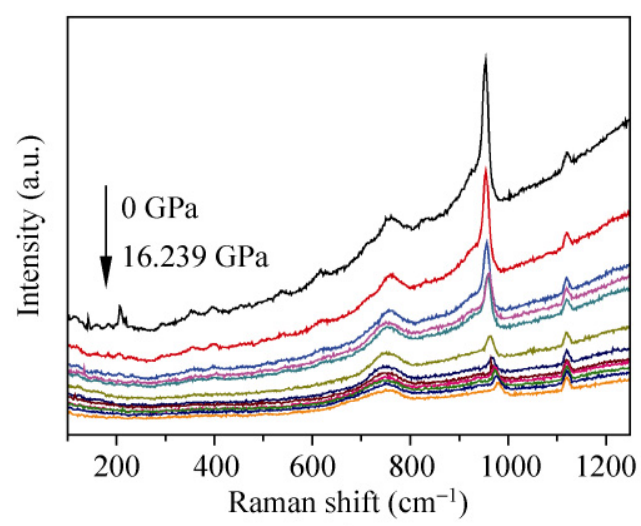

(b)

Figure 5 (a) Pressure-dependent PL spectra of the $\operatorname{AgIn}\left(\mathrm{WO}_{4}\right)_{2}$ mesocrystals (sample 3 in Table 1). The excitation wavelength was 514 nm and the spectra were recorded at room temperature and different pressures, namely $0,0.522,0.934,1.788,2.783,4.088,6.686,8.714$, 9.846, 11.496, 12.839, 14.304, and $16.239 \mathrm{GPa}$. The insert image shows the relationship between the integrated area of the emission peak and the pressure from 0 to $16.239 \mathrm{GPa}$. (b) Raman spectra of the $\mathrm{AgIn}\left(\mathrm{WO}_{4}\right)_{2}$ mesocrystals (sample 3) at room temperature and different pressures, namely $0,0.522,0.934,1.788,2.783,4.088,6.686,8.714,9.846,11.496,12.839,14.304$, and $16.239 \mathrm{GPa}$ 
Temperature-dependent changes in the luminescence spectra of $\operatorname{AgIn}\left(\mathrm{WO}_{4}\right)_{2}$ mesocrystals (sample 3 in Table 1) were investigated down to $10 \mathrm{~K}$ (Fig. 6). At $10 \mathrm{~K}$, the spectrum exhibited a broad emission band around $560 \mathrm{~nm}$. When the temperature was increased from 10 to $300 \mathrm{~K}$, there was no observable shift of the emission band at $560 \mathrm{~nm}$, and its intensity decreased monotonically and slowly. The structure of the mesocrystals was also studied by XRD at different temperatures. The XRD patterns showed that changing the temperature did not alter the structure of the mesocrystals (sample 3 in Table 1) (Fig. 6(b)). Wang et al. [49] have explained the low-temperature luminescence of $\mathrm{ZnWO}_{4}$ single crystals using the theory of electron-phonon interactions. As the temperature increases, the interactions between electronic transitions and phonons associated with defects in a tungsten group become stronger, which might be responsible for the decrease in emission intensities and the shifts of the emission bands. However, more work is required to develop a detailed mechanism for the temperaturedependent changes in the luminescence properties of these $\mathrm{AgIn}\left(\mathrm{WO}_{4}\right)_{2}$ materials.

\section{Conclusions}

Hierarchical silver indium tungsten oxide $\left(\mathrm{AgIn}\left(\mathrm{WO}_{4}\right)_{2}\right)$ mesocrystals with different morphologies can be synthesized by tuning the initial concentrations of the precursors in a microwave-assisted synthesis method. By adjusting the initial concentrations, materials with different amounts of crystalline outgrowths were obtained. The photoluminescence spectra of five $\operatorname{AgIn}\left(\mathrm{WO}_{4}\right)_{2}$ mesocrystals with different morphologies have been compared. The materials all showed a white emission in the visible region when excited by visible light of wavelength $460 \mathrm{~nm}$. The amount of outgrowths in the $\operatorname{AgIn}\left(\mathrm{WO}_{4}\right)_{2}$ materials has an important effect on their photoluminescence properties, namely the greater the amount of outgrowths, the stronger the emission intensity. In addition, pressure has a significant influence on the emission intensity. It was found that $8.714 \mathrm{GPa}$ was a critical value of the pressure, at which the crystals underwent a pressureinduced phase transition resulting in changes in its crystal field. The intensity of the emission band at $560 \mathrm{~nm}$ decreased with increasing temperature. These hierarchical $\mathrm{AgIn}\left(\mathrm{WO}_{4}\right)_{2}$ mesocrystals are expected to be of interest for both fundamental research and optical applications in the future.

\section{Acknowledgements}

S. H. Y. acknowledges the special funding support from the National Basic Research Program of China (No. 2010CB934700), the National Natural Science Foundation of China (NSFC, No. 50732006), the Program of International S \& $\mathrm{T}$ Cooperation (No.

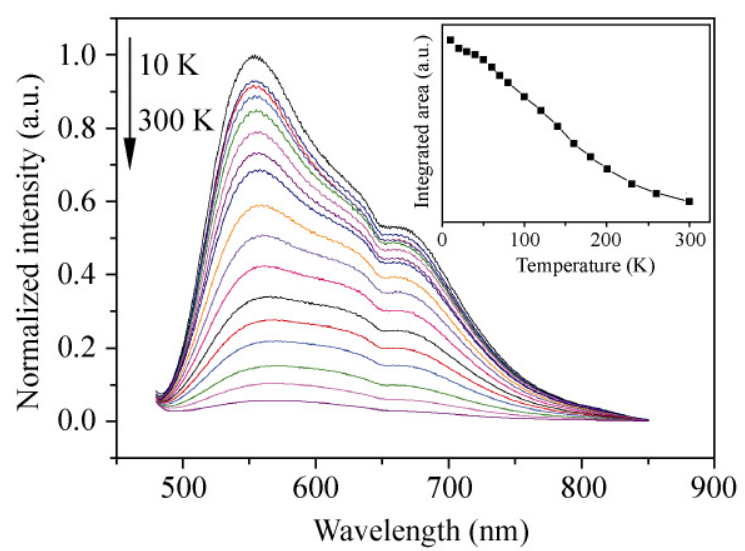

(a)

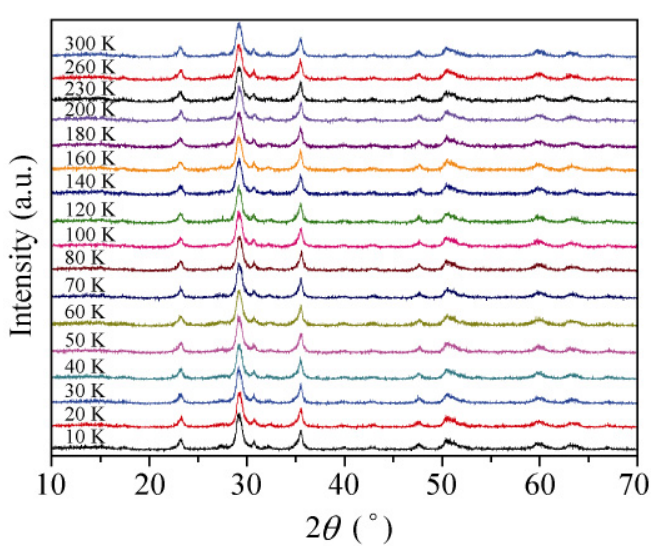

(b)

Figure 6 (a) Temperature-dependent PL spectra of the $\operatorname{AgIn}\left(\mathrm{WO}_{4}\right)_{2}$ materials (sample 3 in Table 1). The excitation wavelength was $460 \mathrm{~nm}$ and the spectra were recorded at different temperatures, namely 10, 20, 30, 40, 50, 60, 70, 80, 100, 120, 140, 160, 180, 200, 230, 260, and $300 \mathrm{~K}$. The insert image shows the relationship between the integrated area of the emission peak and the temperature from 10 to $300 \mathrm{~K}$. (b) The XRD patterns of the $\mathrm{AgIn}\left(\mathrm{WO}_{4}\right)_{2}$ materials (sample 3) at different temperatures from 10 to $300 \mathrm{~K}$ 
2010DFA41170), and the Principal Investigator Award by the National Synchrotron Radiation Laboratory at the University of Science and Technology of China.

Electronic Supplementary Material: SEM and TEM images of silver indium tungsten oxide particles, and UV-visible absorption spectra are available in the online version of this article at http://dx.doi.org/10.1007/ s12274-010-1044-y and are accessible free of charge.

Open Access: This article is distributed under the terms of the Creative Commons Attribution Noncommercial License which permits any noncommercial use, distribution, and reproduction in any medium, provided the original author(s) and source are credited.

\section{References}

[1] Alivisatos, A. P. Perspectives on the physical chemistry of semiconductor nanocrystals. J. Phys. Chem. 1996, 100, 13226-13239.

[2] Li, Y. C.; Ye, M. F.; Yang, C. H.; Li, X. H.; Li, Y. F. Composition- and shape-controlled synthesis and optical properties of $\mathrm{Zn}_{x} \mathrm{Cd}_{1-x} \mathrm{~S}$ alloyed nanocrystals. Adv. Funct. Mater. 2005, 15, 433-441.

[3] Murray, C. B.; Kagan, C. R.; Bawendi, M. G. Synthesis and characterization of monodisperse nanocrystals and closepacked nanocrystal assemblies. Annu. Rev. Mater. Sci. 2000, 30, 545-610.

[4] Kozma, P.; Bajgar, R.; Kozma, P. Radiation damage of $\mathrm{PbWO}_{4}$ crystals due to irradiation by Co-60 gamma rays. Radiat. Phys. Chem. 2002, 65, 127-130.

[5] Zhou, Y. X.; Yao, H. B.; Zhang, Q.; Gong, J. Y.; Liu, S. J.; Yu, S. H. Hierarchical $\mathrm{FeWO}_{4}$ microcrystals: Solvothermal synthesis and their photocatalytic and magnetic properties. Inorg. Chem. 2009, 48, 1082-1090.

[6] Tanaka, K.; Miyajima, T.; Shirai, N.; Zhuang, Q.; Nakata, R. Laser photochemical ablation of $\mathrm{CdWO}_{4}$ studied with the time-of-flight mass-spectrometric technique. J. Appl. Phys. 1995, 77, 6581-6587.

[7] Qu, W. M.; Wlodarski, W.; Meyer, J. U. Comparative study on micromorphology and humidity sensitive properties of thinfilm and thick-film humidity sensors based on semiconducting $\mathrm{MnWO}_{4}$. Sens. Actuat. B 2000, 64, 76-82.

[8] Ehrenberg, H.; Weitzel, H.; Heid, C.; Fuess, H.; Wltschek, G.; Kroener, T.; van Tol, J.; Bonnet, M. Magnetic phase diagrams of $\mathrm{MnWO}_{4}$. J. Phys.: Condens. Matter 1997, 9, 3189-3203.

[9] Liu, B.; Yu, S. H.; Li, L. J.; Zhang, Q.; Zhang, F.; Jiang, K.
Morphology control of stolzite microcrystals with high hierarchy in solution. Angew. Chem. Int. Edit. 2004, 43, 4745-4750.

[10] Zhang, Q.; Chen, X. Y.; Zhou, Y. X.; Zhang, G. B.; Yu, S. H. Synthesis of $\mathrm{ZnWO}_{4} @ \mathrm{MWO}_{4}(\mathrm{M}=\mathrm{Mn}, \mathrm{Fe})$ core-shell nanorods with optical and antiferromagnetic property by oriented attachment mechanism. J. Phys. Chem. C 2007, 111, 3927-3933.

[11] Zhang, Q.; Yao, W. T.; Chen, X. Y.; Zhu, L. W.; Fu, Y. B.; Zhang, G. B.; Sheng, L. S.; Yu, S. H. Nearly monodisperse tungstate $\mathrm{MWO}_{4}$ microspheres $(\mathrm{M}=\mathrm{Pb}, \mathrm{Ca})$ : Surfactantassisted solution synthesis and optical properties. Cryst. Growth Des. 2007, 7, 1423-1431.

[12] Su, Y. G.; Li, G. S.; Xue, Y. F.; Li, L. P. Tunable physical properties of $\mathrm{CaWO}_{4}$ nanocrystals via particle size control. J. Phys. Chem. C 2007, 111, 6684-6689.

[13] Su, Y. G.; Li, L. P.; Li, G. S. Synthesis and optimum luminescence of $\mathrm{CaWO}_{4}$-based red phosphors with codoping of $\mathrm{Eu}^{3+}$ and $\mathrm{Na}^{+}$. Chem. Mater. 2008, 20, 6060-6067.

[14] Su, Y. G.; Li, L. P.; Li, G. S. Self-assembly and multicolor emission of core/shell structured $\mathrm{CaWO}_{4}: \mathrm{Na}^{+} / \mathrm{Ln}^{3+}$ spheres. Chem. Commun. 2008, 4004-4006.

[15] Gautam, U. K.; Fang, X. S.; Bando, Y.; Zhan, J. H.; Golberg, D. Synthesis, structure, and multiply enhanced field-emission properties of branched $\mathrm{ZnS}$ nanotube-In nanowire core-shell heterostructures. ACS Nano 2008, 2, 1015-1021.

[16] Zhai, T. Y.; Fang, X. S.; Bando, Y. S.; Liao, Q.; Xu, X. J.; Zeng, H. B.; Ma, Y.; Yao, J. N.; Golberg, D. Morphologydependent stimulated emission and field emission of ordered CdS nanostructure arrays. ACS Nano 2009, 3, 949-959.

[17] Li, Y.; Xiang, J.; Qian, F.; Gradecak, S.; Wu, Y.; Yan, H.; Yan, H.; Blom, D. A.; Lieber, C. M. Dopant-free $\mathrm{GaN} / \mathrm{AlN} / \mathrm{AlGaN}$ radial nanowire heterostructures as high electron mobility transistors. Nano Lett. 2006, 6, 1468-1473.

[18] Xu, L.; Su, Y.; Li, S.; Chen, Y. Q.; Zhou, Q. T.; Yin, S.; Feng, Y. Self-assembly and hierarchical organization of $\mathrm{Ga}_{2} \mathrm{O}_{3} / \mathrm{In}_{2} \mathrm{O}_{3}$ nanostructures. J. Phys. Chem. B 2007, 111, 760-766.

[19] Jung, Y.; Ko, D. K.; Agarwal, R. Synthesis and structural characterization of single-crystalline branched nanowire heterostructures. Nano Lett. 2007, 7, 264-268.

[20] Zhai, T. Y.; Fang, X. S.; Bando, Y.; Dierre, B.; Liu, B. D.; Zeng, H. B.; Xu, X. J.; Huang, Y.; Yuan, X. L.; Sekiguchi, T.; Golberg, D. Characterization, cathodoluminescence, and field-emission properties of morphology-tunable CdS micro/ nanostructures. Adv. Funct. Mater. 2009, 19, 2423-2430.

[21] Banerjee, D.; Jo, S. H.; Ren, Z. F. Enhanced field emission of $\mathrm{ZnO}$ nanowires. Adv. Mater. 2004, 16, 2028-2032.

[22] Fang, X. S.; Gautam, U. K.; Bando, Y.; Dierre, B.; Sekiguchi, T.; Golberg, D. Multiangular branched $\mathrm{ZnS}$ 
nanostructures with needle-shaped tips: Potential luminescent and field-emitter nanomaterial. J. Phys. Chem. C 2008, 112, 4735-4742.

[23] He, J. H.; Yang, R. S.; Chueh, Y. L.; Chou, L. J.; Chen, L. J.; Wang, Z. L. Aligned AIN nanorods with multi-tipped surfaces: Growth, field-emission, and cathodoluminescence properties. Adv. Mater. 2006, 18, 650-654.

[24] Yang, R. S.; Chueh, Y. L.; Morber, J. R.; Snyder, R.; Chou, L. J.; Wang, Z. L. Single-crystalline branched zinc phosphide nanostructures: Synthesis, properties, and optoelectronic devices. Nano Lett. 2007, 7, 269-275.

[25] El-Sayed, M. A. Small is different: Shape-, size-, and composition-dependent properties of some colloidal semiconductor nanocrystals. Acc. Chem. Res. 2004, 37, 326-333.

[26] Sun, Y. J.; Chen, Y.; Tian, L. J.; Yu, Y.; Kong, X. G.; Zhao, J. W.; Zhang, H. Controlled synthesis and morphology dependent upconversion luminescence of $\mathrm{NaYF}_{4}: \mathrm{Yb}, \mathrm{Er}$ nanocrystals. Nanotechnology 2007, 18, 275609.

[27] Sun, Y. J.; Chen, Y.; Tian, L. J.; Yu, Y.; Kong, X. G.; Zeng, Q. H.; Zhang, Y. L.; Zhang, H. Morphology-dependent upconversion luminescence of $\mathrm{ZnO}: \mathrm{Er}^{3+}$ nanocrystals. $J$. Lumin. 2008, 128, 15-21.

[28] Das, K.; Sharma, S. N.; Kumar, M.; De, S. K. Morphology dependent luminescence properties of Co doped $\mathrm{TiO}_{2}$ nanostructures. J. Phys. Chem. C 2009, 113, 14783-14792.

[29] Shen, J. M.; Li, J. Y.; Chen, Y.; Huang, Z. Construction of unconventional hexapod-like tellurium nanostructure with morphology-dependent photoluminescence property. J. Phys. Chem. C 2009, 113, 9502-9508.

[30] Kan, S. H.; Mokari, T.; Rothenberg, E.; Banin, U. Synthesis and size-dependent properties of zinc-blende semiconductor quantum rods. Nat. Mater. 2003, 2, 155-158.

[31] Zhai, T. Y.; Fang, X. S.; Bando, Y. S.; Liao, Q.; Xu, X. J.; Zeng, H. B.; Ma, Y.; Yao, J. N.; Golberg, D. Morphologydependent stimulated emission and field emission of ordered CdS nanostructure arrays. ACS Nano 2009, 3, 949-959.

[32] Hu, B.; Wu, L. H.; Liu, S. J.; Yao, H. B.; Shi, H. Y.; Li, G. P.; Yu, S. H. Microwave-assisted synthesis of a new silver indium tungsten oxide mesocrystal: Selective photocatalytic properties. Chem. Commun. 2010, 2277-2279.

[33] Barnett, J. D.; Block, S.; Piermarini, G. J. An optical fluorescence system for quantitative pressure measurement in the diamond-anvil cell. Rev. Sci. Instrum. 1973, 44, 1-9.

[34] Yu, S. H.; Liu, B.; Mo, M. S.; Huang, J. H.; Liu, X. M.; Qian, Y. T. General synthesis of single-crystal tungstate nanorods/nanowires: A facile, low-temperature solution approach. Adv. Funct. Mater. 2003, 13, 639-647.

[35] Song, S. Y.; Zhang, Y.; Xing, Y.; Wang, C.; Feng, J.; Shi, W. D.; Zheng, G. L.; Zhang, H. J. Rectangular AgIn $\left(\mathrm{WO}_{4}\right)_{2}$ nanotubes: A promising photoelectric material. Adv. Funct.
Mater. 2008, 18, 2328-2334.

[36] Ovechkin, A. E.; Ryzhikov, V. D.; Tamulaitis, G.; Zukauskas, A. Luminescence of $\mathrm{ZnWO}_{4}$ and $\mathrm{CdWO}_{4}$ Crystals. Phys. Status Solidi A 1987, 103, 285-290.

[37] Polak, K.; Nikl, M.; Nitsch, K.; Kobayashi, M.; Ishii, M.; Usuki, Y.; Jarolimek, O. The blue luminescence of $\mathrm{PbWO}_{4}$ single crystals. J. Lumin. 1997, 72-74, 781-783.

[38] Blasse, G. Classical phosphors: A Pandora's box. J. Lumin. 1997, 72-74, 129-134.

[39] Nikl, M. Wide band gap scintillation materials: Progress in the technology and material understanding. Phys. Status Solidi. A 2000, 178, 595-620.

[40] Tang, J. W.; Zou, Z. G.; Ye, J. H. Photophysical and photocatalytic properties of $\mathrm{AgInW}_{2} \mathrm{O}_{8}$. J. Phys. Chem. B 2003, 107, 14265-14269.

[41] Sun, Y. J.; Chen, Y.; Tian, L. J.; Yu, Y.; Kong, X. G.; Zeng, Q. H.; Zhang, Y. L.; Zhang, H. Morphology-dependent upconversion luminescence of $\mathrm{ZnO}: \mathrm{Er}^{3+}$ nanocrystals. $J$. Lumin. 2008, 128, 15-21.

[42] van Dijken, A.; Meulenkamp, E. A.; Vanmaekelbergh, D.; Meijerink, A. The kinetics of the radiative and nonradiative processes in nanocrystalline $\mathrm{ZnO}$ particles upon photoexcitation. J. Phys. Chem. B 2000, 104, 1715-1723.

[43] van Dijken, A.; Meulenkamp, E. A.; Vanmaekelbergh, D.; Meijerink, A. Identification of the transition responsible for the visible emission in $\mathrm{ZnO}$ using quantum size effects. $J$. Lumin. 2000, 90, 123-128.

[44] van Dijken, A.; Meulenkamp, E. A.; Vanmaekelbergh, D.; Meijerink, A. The luminescence of nanocrystalline $\mathrm{ZnO}$ particles: The mechanism of the ultraviolet and visible emission. J. Lumin. 2000, 87-89, 454-456.

[45] Su, F. H.; Fang, Z. L.; Ma, B. S.; Ding, K.; Li, G. H.; Xu, S. J. Temperature and pressure behavior of the emission bands from $\mathrm{Mn}-, \mathrm{Cu}-$, and Eu-doped $\mathrm{ZnS}$ nanocrystals. J. Appl. Phys. 2004, 95, 3344-3349.

[46] Paszkowicz, W.; Szuszkiewicz, W.; Dynowska, E.; Domagala, J. Z.; Firszt, F.; Meczynska, H.; Legowski, S.; Lathe, C. High-pressure structural and optical properties of wurtzitetype $\mathrm{Zn}_{1-x} \mathrm{Mg}_{x}$ Se. J. Alloy. Compd. 2004, 371, 168-171.

[47] Tang, X. D.; Ding, Z. J.; Zhang, Z. M. Photoluminescence study of $\mathrm{Nd}: \mathrm{YVO}_{4}$ under high pressure. J. Lumin. 2007, 122-123, 66-69.

[48] Shan, W.; Walukiewicz, W.; Ager, J. W.; Yu, K. M.; Yuan, H. B.; Xin, H. P.; Cantwell, G.; Song, J. J. Nature of room-temperature photoluminescence in $\mathrm{ZnO}$. Appl. Phys. Lett. 2005, 86, 191911.

[49] Wang, H.; Medina, F. D.; Liu, D. D.; Zhou, Y. D. The line-shape and zero-phonon line of the luminescence spectrum from zinc tungstate single-crystals. J. Phys.: Condens. Mat. 1994, 6, 5373-5386. 